https://doi.org/10.48009/2_iis_2005_90-95

\title{
QUALITATIVE APPROACHES TO KNOWLEDGE MANAGEMENT ASSESSMENT
}

\author{
Martin Grossman, Bridgewater State College, mgrossman@bridgew.edu \\ Richard V. McCarthy, Quinnipiac University, rmccarthy@quinnipiac.edu
}

\begin{abstract}
Traditional accounting methods have proven insufficient to adequately reflect the value of an organization's intangible knowledge-based resources. Over the past decade many new methods have been introduced that recognize the multifaceted nature of intellectual capital and that include non-financial indicators as well as purely financial ones. However, the current array of instruments still generally rely exclusively on quantitative measures and fall short of capturing many of the subtleties involved with intellectual capital. This paper examines the growing role that qualitative techniques are playing in assessing intellectual capital and knowledge management within organizations. Several current approaches are described and possible research directions suggested.
\end{abstract}

Keywords: Knowledge management, intellectual capital, KM metrics, KM measurement, qualitative methods

\section{INTRODUCTION}

In today's business environment, knowledge is considered to be the most important driver behind sustained competitive advantage [6]. However, the knowledge-based resources of a company, also referred to as intellectual capital (IC), are intangible in nature and therefore defy easy definition and quantification. Although the discrepancies between a firm's book and market value are by now well-known, the traditional accounting paradigm is still poorly equipped to deal with such elusive concepts as intangible assets.

Over the past decade, the field of knowledge management has grown astronomically and with it a growing cadre of information technologies to support it (e.g. collaborative systems, intranets, enterprise knowledge portals, Communities of Practice). Managers are hard pressed to show a return on investment for such KM related initiatives and the call for better assessment techniques and standards has accelerated. Concurrently with this surge of interest in knowledge management, there has been an intense and urgent interest emanating from the accounting profession to arrive at newer metrics for measuring and reporting intellectual capital. In general the literature is long on theoretical frameworks but short on empirical evidence. In spite of the recent attention to $\mathrm{KM}$ and IC assessment, only $4 \%$ of companies consider their KM measurement efforts to be effective, according to an Ernst \& Young survey [3].

Some attempts to capture intellectual capital, such as Tobin's Q and EVA, are primarily financial in nature and adhere to the dictates of the traditional accounting model [2]. Other approaches go 
beyond a strictly financial perspective and include a number of non-financial indicators relating to customer, process, learning, and human factors [9]. A plethora of assessment methods have surfaced, each with its own framework and set of metrics. Some approaches consider many indicators to be advantageous while others warn against using too many metrics. Still others attempt to reduce all indicators into a single IC index [2]. To date, the methods of IC measurement are still undergoing consolidation and no true consensus has been reached.

\section{A NEED FOR MORE BALANCED ASSESSMENT TECHNIQUES}

Although the majority of current tools have come a long way in recognizing the need for nonfinancial performance indicators, they still rely for the most part on 'hard' quantitative data and on the traditional accounting model for reporting. A number of researchers have questioned the legitimacy of such approaches. Malhotra [9] for example, claims that the majority of today's measures are still too heavily influenced by accounting and financial perspectives and that a 'disconnect' results from not adequately recognizing the influence of other factors (e.g. sociological and psychological) that may impact performance outcomes. Thus, richer modes of assessing the social and behavioral issues that underlie knowledge management (e.g. influence, persuasion, self-determination, commitment and motivation) are needed.

Liebowitz and Suen [8] assert that many existing quantifiable measures lack creativity and fail to address the really valuable types of knowledge, namely those that produce the most value-added benefits for the organization. The authors suggest a number of new metrics that need to be incorporated in an audit of a firm's intellectual capital, among them being the number of 'serious' anecdotes presented about the value of the organization's knowledge management systems. This is consistent with the advice of the American Productivity and Quality Center (APQC), who advocates the generous use of stories and other anecdotal forms, to enliven and explain calculated metrics [1] as well as that of Martin [11] who warns that "...room must be left for the inclusion of other, non-quantitative approaches such as the use of anecdotal and case study evidence for the impact of initiatives employing intangible resources."

Marr and Spender [10] suggest that we need an organic approach, which views knowledge as dynamic and fleeting and combines data, information and practice. It is a view of knowledge in action that takes into account the embedded skills and organizational routines, which may be isolated from management's plans. Such an approach would acknowledge the 'unintended consequences' of management plans, implying that managers never really have complete control over the organization. It is this organic perspective, according to the authors, that is most closely in sync with today's organizational reality in that it recognizes the more dynamic and complex nature of organizational knowledge. As such, a different type of measurement is warranted for this view of knowledge and consequently, a greater reliance on qualitative methods. Some measurement approaches might include: mapping of dependent and independent relationships, narratives, and pattern recognition.

Beccera-Fernandez et al. [3] call for a blending of both qualitative and quantitative assessment measures as a way to get the most complete picture. Qualitative KM assessment strategies are most suitable during the early stages of the KM initiative, when experience level is generally low. Such techniques might include (1) informal chatting with employees about how things are 
going, (2) semi-structured and structured interviews, and (3) accumulation of anecdotal evidence, indicating success or failure of various efforts. As the organization gains more KM experience, a greater reliance on quantitative assessment techniques might be called for. However, qualitative techniques are extremely important throughout the entire initiative and can be particularly useful in environments in which there is a lot of uncertainty.

The 'quantitative vs. qualitative' dichotomy is certainly nothing new. Quantitative methods, originally developed in the natural sciences to study natural phenomena, are well accepted in the social sciences and include techniques such as surveys, lab experiments, and numerical methods (e.g. mathematical modeling). Qualitative methods, on the other hand, rely more on nonnumerical forms of information, and are more appropriate to study social and cultural phenomena. Qualitative methods such as action research, case studies, and ethnography typically include direct observation, interviews, documents and texts, as well the researcher's impressions and reactions [14]. A qualitative approach would be preferable when the goal is to understand the contextual information regarding the way people live. Some researchers utilize a blended approach, called 'triangulation', which combines both quantitative and qualitative methods in one study [14]. Since organizational intellectual capital is inherently intangible and influenced by a complex web of sociopolitical and cultural factors, the benefits of using a blended assessment approach are obvious.

\section{SOME QUALITATIVE ASSESSMENT APPROACHES}

With the rising popularity of knowledge management, we have seen a resurgence of interest in the age old human behavior of storytelling. Current managerial thinking considers stories, anecdotes and narratives as essential vehicles for the transfer of tacit knowledge within the organization [4]. In spite of this current trend, most IC and KM assessment techniques are still locked into the traditional accounting paradigm and fail to incorporate any form of story or narrative into the mix. However, there are some exceptions, explored in the following sections.

\section{The European Connection}

Perhaps the strongest advocacy for incorporating narratives into the IC assessment process comes from the European IC community. One initiative, originally commissioned by the Danish Agency for Trade and Industry, resulted in a new type of IC reporting format called the intellectual capital statement [5]. The intellectual capital statement is considered an integral part of a company's knowledge management strategy which also communicates how a company generates value for employees, customers, partners and investors. Essentially, it is meant to show how well a company has improved the development and management of its knowledge resources (employees, customers, processes, and technologies). This is accomplished by first establishing the need for KM, developing a set of initiatives to improve KM, and finally developing a set of indicators to define, measure and follow up on initiatives. The first element, the knowledge narrative, expresses how knowledge should lead to increases in value to the customer. It would include descriptions of (1) the product or service provided by the company, (2) what makes a difference for the customer, (3) what knowledge resources are necessary to supply the product or service, and (4) what is the relationship between value and knowledge resources. The second 
element is a set of management challenges detailing which existing knowledge resources should be strengthened and what new knowledge resources are needed. The third element consists of initiatives which deal with specific ways to deal with the management challenges, i.e. how to develop, procure and monitor knowledge resources. The fourth and final element is composed of indicators, which allow follow-up on whether the initiatives have been successfully been launched and if they are meeting the specified challenges. Together, these four interrelated elements represent an analysis and assessment of the management of knowledge within the organization.

Another approach, heavily dependent upon a narrative component, comes from the MERITUM project, a European Commission funded initiative which incorporated inputs from IC researchers in Sweden, Norway, Denmark, Finland, France and Spain [13]. Like the intellectual capital statement, MERITUM's intellectual capital report is a format which incorporates several elements: (1) a vision of the firm, (2) a summary of intangible resources and activities, and (3) a system of indicators. The first step, detailing the firm's vision, is much like the knowledge narrative of the intellectual capital statement [5]. The vision of the firm is a narrative that identifies (1) the company's present and future strategic objectives and how they add value for its customers and other stakeholders. (2) the company's most critical intangibles that enable the accomplishment of the strategic objectives through value-creating knowledge processes, and (3) the critical intangibles needed for the future and a description of those that need to be acquired or internally developed. Taken with the other two components of the report, this approach enables the reader to better understand the company's value creation processes as well as the contribution of its intangibles to this process.

Professors Roslender and Fincham from the University of Stirling in the UK [15] present yet another model, called the intellectual capital self-account, which builds on the narrative approaches of the DATI and MERITUM initiatives. Like the previous methods, this approach relies on 'accounts' or stories to reveal various aspects of the resources within the organization. However, the narratives in this method are self-narratives, i.e. they are provided by the organizational participants themselves, rather than others on their behalf. The intellectual capital self-account is meant to allow intellectual capital to speak for itself, rather than being translated by others. Thus, this approach can be viewed as an attempt to promote an 'emancipatory praxis', empowering participants to identify problems by raising their consciousness. In the words of the authors, the self-accounting provided by this technique is "...conceived of as a fundamentally democratic process, characterized by a defining inclusively that is wholly at odds with the exclusive mode of accounting that has, to this point, colonized the development of intellectual capital accounting".

\section{A Program Evaluation/Organizational Development Perspective}

Another interesting assessment approach comes from neither the KM nor the IC communities, but rather from the program evaluation and organizational development worlds. McClintock [12] argues for an assessment approach combining aspects of both of these fields. Program evaluation, although traditionally based on quantitative methods, has evolved to become broader in its scope, utilizing a wider array of empirical methods as part of the evaluation process (e.g. qualitative and mixed methods, case studies, participatory and empowerment action research, and interpretive and constructivist versions of knowledge) [12]. The related field of organization 
development differs from program evaluation in that its focus is on such issues as trust, communication, diagnosis, negotiation, motivation and change dynamics. Drawing from both of these fields, the described framework uses narratives and stories as a critical part of the evaluative process, providing the following advantages: (1) it is amenable to participatory change processes because it relies on people to make sense of their own experiences and environments., (2) it focuses on particular interventions while also reflecting on the array of contextual factors that influence outcomes, (3) it can be systematically gathered and claims verified from independent sources or methods., (4) it can be analyzed using existing conceptual frameworks or assessed for emergent themes, (5) it can be integrated into ongoing organizational processes to aid in program planning, decision making, and strategic management.

Three different narrative-based approaches are described which, although not originally meant to evaluate KM or IC, are appealing conceptually and easily applicable to a KM/IC assessment context. One such technique, called the most significant change approach, relies heavily on narratives and storytelling as a key element in the evaluative process. Steps include (1) domains of inquiry for storytelling are identified, (2) formats for data collection are identified, (3) stories are selected by stakeholders who vote for those accounts best representing a program's value and desired outcomes, and (4) conduct a content analysis of all stories. An important consideration is that the story selection process becomes as important as the data itself in the stories. Here we see yet another example of participatory involvement in the assessment process, similar to the 'emancipatory' aspects of the IC self-account described above [15 ] and consistent with some qualitative techniques such as action research [14 ].

Another approach is the success case method which is composed of two primary phases: (1) an email survey is sent to all program participants to identify those who benefited and those who did not. (2) extreme cases on either end of spectrum are identified and the respondents asked to tell stories about both the features of the program that were or not helpful as well as other organizational factors that facilitated or impeded success. Thus, independent evidence is obtained via a storytelling interview that can corroborate success factors. Again, the assessment approach is conceived of as a management tool, i.e. the stories serve both to document outcomes and also to guide management about changes that are necessary to accomplish broader organizational performance goals.

Finally, an evaluation approach is described that depends on qualitative case studies. Stories are used to understand the contextual and cultural aspects of participants' experiences with a particular program and to explain outcomes. This method may involve an assortment of techniques, such as site visits, review of documents, participant observation, and interviews.

\section{CONCLUSION}

Approaches integrating both quantitative and qualitative approaches can be utilized to assess IC within the organization, and/or the efficacy of specific KM initiatives. Most modern IC assessment techniques, while considering non-financial indicators, still rely predominantly on quantitative measures. In this paper, we explored the use of qualitative methods as a way to enrich the assessment process. Such text forms as narratives, stories, anecdotes are rich in contextual information, and provide an alternative way to tap into some of the more tacit and 
complex elements of intellectual capital. Several approaches based on narratives were reviewed. Future studies will examine the feasibility of using qualitative software applications as part of the assessment process. Such applications may be useful to add a deeper level of narrative analysis, combining a number of techniques for linking data, shaping data into sets, coding processes, and modeling and searching.

\section{REFERENCES}

1. American Productivity and Quality Center (2004). Five tips to measure the impact of knowledge management. [ Available at http://www.apqc.org]

2. Andriessen, D. (2004). Making sense of intellectual capital: Designing a method for the valuation of intangibles. Elsevier Butterworth-Heinemann.

3. Beccerra-Fernandez, I., Gonzalez, A. \& Sabherwal, R. (2004). Knowledge Management: Challenges, Solutions and Technologies. Upper Saddle River, NJ. Pearson- Prentice Hall.

4. Brown, J. S., Denning, S., Groh, K, \& Prusak, L. (2005). Storytelling in organizations: Why storytelling is transforming $21^{\text {st }}$ century organizations and management. Elsevier Butterworth-Heinemann. Burlington, MA.

5. DATI (2003). Intellectual capital statements - The new guideline. Danish Ministry of Science, Technology and Innovation.

6. Grant, R. M. (1996). Toward a knowledge-based theory of the firm. Strategic Management Journal, 17. 109-122.

7. Kannan, G. \& Aulbur, W. G. (2004). Intellectual capital: Measurement effectiveness. Journal of Intellectual Capital, 5(3). 389-413.

8. Liebowitz, J. \& Suen, C. Y (2000). Developing knowledge management metrics for measuring intellectual capital. Journal of Intellectual Capital, 1(1). 54-67.

9. Malhotra, Y. (2003). Measuring knowledge assets of a nation: Knowledge systems for development. Ad Hoc Group of Experts Meeting. United Nations Headquarters. NYC, NY. September 4-5, 2003.

10. Marr, B. \& Spender, J. C. (2004). Measuring knowledge assets: Implications of the knowledge economy for performance measurement. Measuring Business Excellence, 8(1). $18-27$.

11. Martin, J. W. (2004). Demonstrating knowledge value: a broader perspective on metrics. Journal Of Intellectual Capital, 5(1), 77-91.

12. McClintock, C. (2003). Using narrative methods to link program evaluation and organization development. The Evaluation Exchange, 4(4), 14-16.

13. MERITUM (2002). Guidelines for Managing and Reporting on Intangibles.

14. Myers, M. D. (1997). Qualitative research in information systems. MIS Quarterly, 21(2), 241-242.

15. Roslender, R. \& Fincham, R. (2003). Intellectual capital: Who counts, controls? Proceedings of Critical Management Studies, July, 7-9. Lancaster University, England. 